\title{
ANAK JALANAN DI KOTA KENDARI MENUJU KOTA LAYAK ANAK
}

\author{
Masdin'), Beti Mulu $^{2)}$ \\ ${ }^{1)}$ Fakultas Tarbiyah dan Ilmu Keguruan Institut Agama Islam Negeri \\ Kendari; \\ ${ }^{2)}$ Fakultas Ekonomi dan Bisnis Islam Institut Agama Islam Negeri \\ Kendari
}

Koresponden Author: Masdin_67@yahoo.co.id

\begin{abstract}
Street children in Kendari are as same as other children in the universe who have the right to get education and play around. This study aims to analyze the street children phenomenon within the framework child-friendly-city (KLA). Some of the street children in Kendari attend formal school and some of them take informal one, especially in one of street children communities in Kendari; called KOJAK, or most of them do not attend any educational institutions since they encounter financial problem. They make a living in the streets to help their parents' economy condition. Some of them are staying with their parents, but others have no place to live and stay on the road. They work as street musician to fulfill their needs. Recently, there is no special education for street children facilitated by the government. Under KLA framework, the children need to obtain education because it is their right to pursue their dreams in the future. The city government has not facilitated education for street children, and the street children who attend school are initiatives from parents or non-governmental organizations.
\end{abstract}

Key word; education, the street children, child-friendly city

\begin{abstract}
Abstrak
Anak jalanan di Kota Kendari merupakan bagian dari anak secara keseluruhan yang memiliki hak untuk pendidikan dan bermain. Penelitian ini bertujuan untuk menganalisis penomena anak jalan di Kota Kendari dalam kerangka Kendari menuju Kota Layak Anak (KLA). Sebagian dari anak jalanan di kota Kendari bersekolah pada sekolah formal dan sebagian lainnya belajar melalui lembaga komunitas anak jalanan kota Kendari (Kojak), dan yang lainnya putus sekolah dengan alasan tidak mampu secara ekonomi. Anak-anak jalalan di Kota Kendari mencari nafkah dijalanan untuk membantu ekonomi orang tua. Sebagian mereka masih kembali ke orang tua, namun sebagian lainnya tidak memiliki tempat tinggal dan hidup dijalan. Mereka bekerja sebagai pengamen dan pengasong untuk memenuhi kebutuhan ekonomi keluarga. Sejauh ini belum tersedia model pendidikan khusus bagi anak jalanan di Kota Kendari yang difasilitasi oleh
\end{abstract}


pemerintah. Dalam kerangka Kota Layak Anak (KLA) anak jalan perlu mendapatkan akses pendidikan, agar mereka mendapatkan hak belajar demi masa depan mereka. Pemerintah kota kendari belum memfasilitasi pendidikan bagi anak jalan, mereka yang bersekolah merupakan inisiatif dari orang tua atau lembaga swadaya masyarakat.

\section{Kata Kunci: pendidikan, anak jalan, kota layak anak}

\section{A. PENDAHULUAN}

Keberhasilan pembangunan ditentukan oleh sumber daya manusia, dan kualitas sumber daya manusia ditentukan oleh pembangunan kesejahteraan dan perlindungan anak saat ini. Oleh karena itu perlu perubahan paradigma yang menempatkan posisi anak sebagai investasi masa depan, bukan sebagai asset. Terjadinya perubahan global yang mengancam anak dari segi agama, sosial dan budaya, membuat anak semakin menghadapi tantangan yang keras, serta anak terancam menjadi korban kekerasan, pelecehan dan diskriminasi. Meningkatnya jumlah anak di jalanan di Kota besar termasuk kota Kendari, mendorong peningkatan jumlah kriminalitas di jalanan. Data jumlah anak jalanan di kota Kendari yang dirilis Disnakertransos adalah 90 orang $^{1}$. Sementara data Polres Kendari tahun 2016 menyebutkan terdapat 117 anak jalanan ${ }^{2}$. Jumlah ini termasuk anak yang tinggal bersama orang tua dan bekerja menjadi pengemis untuk membantu ekonomi orang tua.

Anak jalanan adalah anak yang menghabiskan sebagian besar waktunya dijalanan untuk bekerja, bermain atau beraktivitas lainnya. ${ }^{3}$ Anak jalanan dibedakan dalam tiga kelompok; (1) Children on the street, yakni anak-anak yang mempunyai kegiatan ekonomi dan sebagai pekerja di jalan, tetapi masih mempunyai hubungan yang kuat dengan orang tua mereka. Hal ini dilakukan untuk membantu ekonomi keluarganya karena beban kemiskinan yang mesti di tanggung tidak dapat diselesaikan sendiri oleh kedua orang tuanya; (2) Children of the street, yakni anak-anak yang berpartisipasi penuh di jalanan, baik secara sosial maupun ekonomi. Beberapa diantara mereka masih mempunyai hubungan dengan orang tuanya, tetapi frekwensi pertemuan mereka tidak menentu, diantara mereka ada yang mengalami kekerasan atau lari dari rumah; (3)Children from family of the street, yakni anak-anak yang berasal dari keluarga yang hidup di jalanan. Meski anak-anak ini mempunyai hubungan kekeluargaan yang

\footnotetext{
${ }^{1}$ Data Dinas Ketenega Kerjaan Trasmigrasi dan Sosial Kota Kendari, 2016.

${ }^{2}$ Kendari Pos, 27 Februari 2016.

${ }^{3}$ Surbakti, dkk. "Anak Jalanan dan Penyakit Sosial". Diakses tanggal 27 Maret 2016.
} 
cukup kuat, tetapi hidup mereka terombang-ambing dari satu tempat ke tempat yang lain. ${ }^{4}$ Salah satu ciri penting dari kategori ini menurut Blanc\&Associate adalah pemampangan kehidupan jalanan sejak masih bayi bahkan sejak masih dalam kandungan. ${ }^{5}$

Berdasarkan studi kementrian Sosial RI, karakteristik anak jalanan pada ciri-ciri fisik dan psikis adalah sebagai berikut; 1) ciri fisik; warna kulit kusam, rambut kemerah-merahan, kebanyakan berbadan kurus, pakaian tidak terurus 2) ciri psikis; mobilitas tinggi, acuh tak acuh, penuh curiga, sangat sensitif, berwatak keras, kreatif, berusia antara 5 sampai dengan 18 tahun, melakukan kegiatan atau berkeliaran di jalanan. ${ }^{6}$

Sedangkan studi yang dilakukan UNICEF pada anak-anak yang dikategorikan children of the street, menunjukkan bahwa motivasi mereka hidup di jalanan bukanlah sekadar kebutuhan ekonomi rumah tangga, melainkan juga karena terjadinya kekerasan dan keretakan rumah tangga orang tuanya. Latar belakang anak-anak memilih hidup di jalanan adalah karena kasus-kasus child abuse (tindakan yang salah pada anak). Mereka juga dikategorikan sebagai kelompok marginal, karena mereka melakukan jenis pekerjaan yang tidak jelas jenjang kariernya, kurang dihargai, dan umumnya juga tidak menjanjikan prospek apapun di masa depan.

Sementara itu, Kabupaten/Kota Layak Anak adalah sistem pembangunan kabupaten/kota yang mengintegrasikan komitmen dan sumber daya pemerintah, masyarakat dan dunia usaha yang terencana secara menyeluruh dan berkelanjutan dalam kebijakan, program dan kegiatan untuk pemenuhan hak-hak anak. ${ }^{8}$ Kota Layak Anak meliputi kota yang aman, nyaman dan berkelanjutan, menyediakan sarana dan prasarana sesuai dengan kebutuhan anak, kota yang memenuhi hak-hak anak (belajar, bermain, dan berekspresi) sesuai dengan tahapan perkembangan.

Menurut Sheri\&Bartlett, dalam pemenuhan kebutuhan anak diperlukan adanya intervensi pencegahan terjadinya bahaya terhadap anak di tempat tinggal mereka, yaitu dengan melakukan modifikasi dan perbaikan di

4 Taylor \& Veale, dalam Fauzi, Ahmad, "Usaha Transformasi Anak Jalanan Keluar Dari Posisi Anak Jalanan (Studi Perilaku Sosial Anak Jalanan Di Provinsi Banten, Jurnal Eksistensi Pendidikan Luar Sekolah (E-Plus), Vol.1. No.1, (2016): 29-49.

${ }^{5}$ Ibid

${ }^{6}$ Ibid.

7 Bagong, Suyanto dan Hariadi, Sri Sanituti, Krisis dan Child Abuse, Kajian Sosiologis tentang Kasus Pelanggaran Hak Anak dan Anak-Anak yang Membutuhkan Perlindungan Khusus (Child in Need of Special Protection). (Surabaya: Airlangga Univercity Press, 2002).

${ }^{8}$ www.kotalayakanak.org, diakses 08 Mei 2017. 
lingkungan tempat tinggal. ${ }^{9}$ Untuk memenuhi indikator konsep Kota Layak Anak tersebut, para pemangku kepentingan terutama pemerintah, harus memahami apa saja hak-hak sipil anak, sehingga perencana kota dan pemerintah daerah dapat menyelenggarakan program dan infrastruktur yang tepat sesuai dengan kebutuhan tanpa melupakan aspek pemenuhan hak-hak anak.

Tujuan konsep kota layak anak (KLA) atau Child friendly City adalah untuk menciptakan suatu kondisi yang menginspirasi hak-hak anak melalui tujuan, kebijakan, program dan struktur pemerintahan lokal. ${ }^{10}$ Melalui konsep ini pula pemerintah di suatu kota mampu memberikan jaminan terhadap hak-hak anak seperti kesehatan, perlindungan, perawatan, pendidikan, dan tidak menjadi korban kekerasan, memiliki kebebasan bermain dan memeroleh lingkungan yang bebas polusi. ${ }^{11}$ Gambaran tentang pentingnya ruang yang luas dan nyaman bagi tumbuh kembang anak, seperti misalnya bahwa jalan memiliki peran sebagai wahana bermain dan tumbuh kembang anak ${ }^{12}$; pendekatan arti penting bentuk kota (urban form) dan struktur sosial adalah untuk menciptakan partisipasi anak di perkotaan ${ }^{13}$; penggunaan ruang terbuka sebagai arena bermain anakanak dapat mengembangkan kesehatan dan kreatifitas anak; perencanaan taman bermain yang ramah anak harus mempertimbangkan kebutuhan anak dalam bermain; $;{ }^{14}$ dengan mempertimbangkan pengamanan dan pengawasan terhadap tempat bermain, anak akan merasa tenang dan nyaman. ${ }^{15}$ Konsepkonsep tersebut menunjukan bahwa pemerintah perlu mempertimbangkan pengamanan dan pengawasan di tempat bermain dan meningkatkan keselamatan anak.

9 Bartlett, Sheridan, "Urban Children and the Physical Environment". Amman, Jordan: International Conference on Childern and The City, 2002.

${ }^{10}$ Child Friendly Cities. "What is a Child Friendly City?

http://www.childfriendlycities.org/en/overview/ what-is-a-child-friendly-city. diakses tanggal 08 Mei 2017.

${ }^{11}$ Riggio, E, "Child Friendly Cities: Good Governance in the Best Interest of the Child”, Journal of Environment and Urbanization, Vol. 14, No. 2, (2002): 45-58.

${ }^{12}$ Karsten, L \& V an Vliet, W, "Children in the City: Reclaiming the Street". International Journal of Youth and Environments, Vol. 16, No. 1, (2006): 151-167.

13 Bridgman, R, "Criteria for Best Practices in Building Child-Friendly Cities: Involving Young People in Urban Planning and Design”, Canadian Journal of Urban Research, Vol. 13, No. 2, (2004): 337- 346.

${ }^{14}$ Hendricks, Barbara. Child Friendly Environments in the City. (Brescia: Ordine Degli Achitetti, 2002), h. 14.

${ }^{15}$ Bartlett, Sheridan..., Loc Cit. 
Pemerintah kota Kendari telah meluncurkan program Kendari kota layak anak yang bebas dari pekerja dan kekerasan terhadap anak dan sebagai upaya melindungi hak-hak mereka. Program ini akan memberikan perlindungan terhadap anak dan hak-haknya dalam proses berkelanjutan. Namun kenyataanya bahwa masih banyak anak yang hidup di jalanan. Kehadiran anak jalan di kota Kendari cukup memprihatinkan, banyaknya anak bekerja dijalanan membantu orang tuanya, membuat mereka tidak punya kesempatan untuk bersekolah atau bahkan bermain seperti layaknya anak seusianya. Dalam kondisi inilah perlu langkah-langkah strategis untuk mengintegrasikan pembangunan yang mengarusutakamakan pendidikan anak, dalam rangka Kendari menuju kota layak anak. Pemerintah kota Kendari perlu mengembangkan program pembangunan berbasis kota layak anak, agar anak-anak usia sekolah tidak lagi menjadi perkerja dijalanan, tetapi dapat menikmati lingkungan yang layak untuk pengembangan dirinya, baik taman bermain, akses pendidikan.

Beerapa penelitian tentang Kota Layak Anak sudah dilakukan sebagaimana yang dilakukan Hamid Pattilima di Kwitang bahwa dengan membangun sarana kebutuhan masyarakat (orang dewasa), pemerintah kota menganggap bahwa kebutuhan anakpun telah terwakili dan terpenuhi dengan sendirinya. Kota yang layak buat anak kriterianya adalah bila mereka main di RT, RW, mereka merasa nyaman, kawasannya aman bagi anak, mengikutsertakan anak dalam pengambilan keputusan, dan berorientasi pada kepentingan anak. ${ }^{16}$ Penelitian Bambang Rustanto menemukan bahwa untuk mewujudkan Kota Layak Anak perlu diperkokoh kemitraan pemerintah dengan para pelaku lain yang akan memberikan kontribusi yang unik.

Penelitian ini adalah kualitatif fenomenologis ${ }^{17}$, dengan menggunakan pendekatan "naturalistic"18. Subjek penelitian adalah anak jalan di kota Kendari, penentuan subjek penelitian didasarkan pada hasil obsevasi dan wawancara terhadap anak jalanan, mereka bersedia mengungkapkan perasaan dan pengalaman mereka selama di jalanan tanpa merasa tertekan. Pengumpulan data menggunakan teknik observasi, interview, dan studi dokumen. Observasi ditujukan untuk menemukan makna interaksi anak jalanan dengan lingkungan. Sedangkan interview

16 http:// megapolitan. kompas.com/, diakses, 10 Juni 2017.

17 Schutz's, A., (1970), "Phenomenology, Ethnomethodology and Interpretative Practice”, in N. K. Denzin \& Yvonna S. Lincoln, Hand Book of Cualitative Research. (Sage Publication Inc. California, 1970). h. 234.

18 Nasution, S, Metode Penelitian Naturalistik Kualitatif, (Bandung: Tarsito, 1996). 
dilakukan untuk mendapatkan gambaran secara mendalam tentang apa yang difikirkan dan dirasakan mereka selama di jalanan. Teknik analisa data menggunakan model Milles, M. B. \& Huberman, data reduction, data display, conclution drawing/ verification. ${ }^{19}$ Reduksi data dengan merangkum data hasil observasi dan wawancara, menganalisis aktivitas anak jalan, untuk mendapatkan gambaran mengenai pendidikan mereka, dengan sistem coding, meringkas kata pendek yang memuat esensi dari suatu segmen data. ${ }^{20}$ Coding ini dilakukan dalam tiga tahap yakni open coding, axial coding dan selective coding. ${ }^{21}$ Setelah ditemukan polanya, selanjutnya dilakukan display data dengan memfokuskan pada askses pendidikan anak jalanan dalam kerangka KLA di kota Kendari ${ }^{22}$, dengan penjelasan secara naratif. Selanjutnya dilakukan conclution/drawing verification untuk penarikan kesimpulan hasil penelitian.

\section{B. KEBERADAAN ANAK JALAN DI KOTA KENDARI}

Anak jalan adalah anak yang menggunakan sebagian atau seluruh waktunya untuk hidup dijalan baik untuk mencari nafkah, atau hanya sekadar bermain dan berkeliaran. Kehadiran anak jalanan di kota Kendari, sering kali dianggap sebagai pengganggu keindahan kota dan ketertiban jalan raya, menyebabkan rawan kecelakaan, dan memberikan perasaan tidak aman dan nyaman bagi masyarakat disebabkan perilaku mereka yang kadang tidak sopan, seperti berkata kotor, memaki, merusak bodi mobil dengan menggores dan lain-lain, apabila tidak diberi uang. Pemerintah kota Kendari seringkali melakukan razia bagi anak jalanan, mereka yang terjaring raziah dikembalikan kepada orang tuanya, namun hal tersebut terbukti tidak efektif karena anak jalanan selalu kembali ke jalan, entah bekerja atau sekedar berkeliaran.

Kehidupan yang keras di jalanan, memaksa anak jalanan untuk bertahan hidup dengan melakukan apa saja, terkadang mereka mendapatkan pelecehan seksual demi mendapatkan uang, tanpa disadari peristiwa tersebut akan berpengaruh pada perilaku yang menyimpang. Apabila hal tersebut dibiarkan, maka menurut Suyanto, ancaman sosial ada di depan mata mereka, seperti kekerasan dan penelantaran, terjerumus minuman

${ }^{19}$ Miles, M., \& Huberman, M, Qualitative Data Analysis: A Source Book fo New Methods, (Beverly Hills, CA: Sage Publications, 1984).

${ }^{20}$ Saldana, Johny, The Coding Manual fo Qualitative Resesarch, (London: Sage Publication, 2009), h. 3

${ }^{21}$ Strauss, A. \& Corbin, J, Basics of Qualitatif Resesrach; Grounded Theory Procedures and Techniqus. (Newbury Park. CA: Sage Publication. Inc, 1990).

${ }^{22}$ Erickson, F., Qualitative Method in Reseach on Teaching. In M. C. Wittrock (Ed.) Handbook of Reseach on Teaching ( $3^{\text {rd }}$ ed. (New York. Macmillan, 1986). h. 362 
keras dan obat-obat terlarang, terserang penyakit menular seksual, eksploitasi seksual, bahkan tidak jarang dijebloskan dalam pelacuran.

Sejauh ini data resmi tentang jumlah anak jalanan di kota kendari yang dirilis Disnakertransos kota kendari adalah 90 orang $^{23}$. Data tersebut belum mencakup seluruh anak jalan di kota Kendari. Anak jalan yang tercatat pada Disnakertransos kota Kendari, adalah mereka yang tinggal di kota Kendari dan tinggal bersama orang tuanya, sementara anak jalanan yang tidak memiliki keluarga di kota Kendari juga lebih banyak. Mereka ini tinggal di emperan toko atau tempat lain yang dianggap lebih aman. Jumlah ini adalah anak yang tinggal bersama orang tua dan bekerja menjadi pengemis untuk membantu ekonomi orang tua. Mereka sebagian bersekolah dan sebagian lainnya putus sekolah. Sementara itu ada lagi komunitas anak jalanan lainnya seperti komunitas Punk (anti kemapanan) yang berjumlah kurang lebih 100 orang. Adalagi komunitas anak jalanan Kendari atau Kojak, mereka ini memiliki sejumlah anggota yang tersebar di Kota Kendari, khusus untuk wilayah Mandonga sebanyak 62 orang. Sementara itu data Polres Kendari tahun 2016 menyebutkan bahwa terdapat 117 anak jalanan ${ }^{24}$.

Anak jalan di kota kendari bukan berasal dari kendari saja tetapi beberapa dari mereka berasal dari daerah lain seperti Sulawesi Selatan, Sulawesi Barat, Kabupaten Muna, dan Kabupaten Buton serta kabupaten lainnya di Sulawesi tenggara. Mereka datang untuk mengais rejeki berdasarkan belas kasihan orang lain karena dikampung asal mereka juga kehidupan sangat susah.

Beberapa tempat di Kota Kendari yang diidentifikasi oleh peneliti sebagai "tempat mangkal" anak jalanan adalah sekitar perempatan hotel Ataya, perempatan masjid Agung, perempatan Tugu Religi Kendari, pasar kota lama, dan pelabuhan Kendari. Diantara anak jalanan di kota Kendari, beberapa yang diorganisir oleh kelompok tertentu. Mereka diantar jemput pagi hari dan didistribusikan pada beberapa titik yang dianggap sering dilewati oleh dermawan pengedara motor atau pengendara mobil terutama pada perempatan traffic light. Pada tempat-tempat tersebut, mereka mengemis, meminta uang belas kasihan pada pengendara yang melewati jalan tersebut, bahkan terkadang mereka menggores kendaran jika penumpangnya tidak memberikan uang. Menurut seorang tukang ojek dan tukang becak, setiap pagi hari didrop oleh seseorang menggunakan mobil, mungkin itulah bos mereka. ${ }^{25}$ Pada siang hari mereka dibagikan nasi dos

${ }^{23}$ Data Dinas Ketenagakerjaan, Trasmigrasi dan Sosial Kota Kendari, 2016

${ }^{24}$ Kendari Pos, 27 Februari 2016.

${ }^{25} \mathrm{X}$...... Wawancara dengan seorang tukang ojek di daerah Mandonga. 
untuk makan siang. Kemudian dijemput lagi malam hari.

Menurut Alam dan Alif, dua anak jalan yang ditemui peneliti mengemukakan bahwa mereka mengamen untuk membatu ekonomi keluarga yang tidak memiliki apa-apa. Alif misalnya telah putus sekolah sejak kelas 3 Sekolah Dasar karena ikut membantu ekonomi keluarga sebagai pengamen di jalan. Orang tua Alif adalah seorang buruh bangunan lepas yang kadang-kadang tidak mendapatkan pekerjaan, Alif terpaksa turun di jalan untuk mencari rezeki buat keluarga. Demikian pula dengan Alam yang putus sekolah sejak kelas 3 Sekolah Dasar, adiknyapun ikut mengamen di jalan untuk membantu ekonomi keluarga. Alam mengamen atas restu orang tuanya. Keingina Alam untuk kembali bersekolah telah pupus karena usianya semakin remaja dan sekarang sudah enam belas tahun. ${ }^{26}$ Bagi Alam pendidikan sudah tidak menjadi prioritas lagi, dia hanya ingin bagaimana keluarganya dapat menyambung kehidupannya untuk besok hari. Naifnya, mereka ini tidak tercatat sebagi anak jalan pada Dinas Tanaga Kerja Transmigrasi dan Sosial Kota Kendari, sekalipun menurut mereka telah lama mengamen dan berpindah pindah dari satu tempat ke tempat lainnya.

Hasil penelitian juga menemukan bahwa di sekitar tempat mangkal dan bermain anak jalanan terlihat bekas lem yang telah mengering di beberapa sudut tembok. Kuat dugaan bahwa tempelan-tempelan itu adalah lem fox pada tembok sebagi tempat membersihkan jari-jari mereka memgang lem. Dari bukti ini dapat dikatakan bahwa anak jalan yang mangkal di sana ada yang sering ngelem.

\section{MODEL DAN AKSES PENDIDIKAN ANAK JALANAN DI KOTA KENDARI DALAM KERANGKA KOTA LAYAK ANAK (KLA)}

Mengatasi anak jalanan tentu bukanlah semata-mata untuk memberikan suasana tertib, nyaman, dan aman bagi warga dalam beraktivitas. Tetapi lebih dari itu, mencarikan solusi bagi anak jalanan saat ini berarti mengurangi masalah sosial yang akan muncul kemudian hari, bahkan menyelamatkan anak tersebut dari kehidupan suram masa kanakkanak dan masa depannya. Sebagai anak-anak, mereka tentunya harus diberi kesempatan untuk menikmati masa kanak-kanak, diberi kesempatan untuk memperoleh pendidikan yang layak, untuk kemudian, suatu saat nanti mereka bisa memanfaatkan potensi dirinya untuk memberikan kontribusi terbaik bagi dirinya dan daerah ini.

Kebanyakan anak jalanan di kota Kendari merupakan anak-anak yang berasal dari keluarga kurang mampu. Berdasarkan hasil penelusuran peneliti bahwa sebahagian anak jalan di kota Kendari putus sekolah sejak

${ }^{26}$ Alam \& Alief, anak jalanan, wawancara, 4 April 2017. 
Sekolah Dasar. Alasan yang paling umum dikemukakan ketika mereka ditemui di jalanan adalah mereka membantu ekonomi orang tua karena orang tua tak mampu lagi membiayai sekolah mereka, bahkan untuk makanpun mereka sangat kesulitan. Menurut mereka bahwa sekolah harus membutuhkan banyak biaya seperti membeli buku, biaya transportasi, membeli seragam sekolah, uang jajan, bahkan biaya lain yang dibutuhkan. Sehingga, mereka dengan berat hati ikut mencari rejeki dengan jalan mengamen di jalanan, meminta uang, menjadi pengasong penjual koran, bahkan kadang-kadang dengan mencuri. Hal ini hanya semata-mata untuk memenuhi kebutuhan hidup keluarganya.

Kehadiran Lembaga Swadaya Masyarakat (LSM) dalam mebantu pendidikan anak jalan di kota Kendari dianggap angin segar bagi masa depan anak jalanan, seperti Komunitas anak jalan Kendari (Kojak), Rumah Keluarga Indonesia (RKI), namun program mereka belum menjangkau seluruh anak jalan di kota Kendari. Pemerintah Kota Kendari hendaknya memfasilitasi pengembangan pendidikan anak jalan dengan membangun rumah singgah, sanggar seni, atau lembaga keterampilan lain yang dapat membantu anak jalan agar memiliki keterampilan untuk masa depan mereka.

Menurut data Dinas Tenaga Kerja Transmigari dan Sosial kota Kendari, tercatat ada 90 anak jalan yang diregistrasi. Pemerintah perlu memberikan bantuan beasiswa untuk bebas SPP, membantu pengadaan seragam sekolah, pengadaan buku-buku, sampai pada jaminan kelangsungan hidup agar mereka tidak lagi kembali ke jalan, karena alasan ekonomi dan biaya sekolah yang tidak ada. Demikian pula pemerintah kota Kendari hendaknya menyediakan fasilitas dan akses pendidikan bagi anak jalan dibeberapa tempat agar dengan mudah mereka dapat mengaksesnya untuk mengkuti pendidikan dan keterampilan yang ditawarkan. Bagi anak jalanan yang telah putus sekolah dan berusia di atas 13 tahun, mereka perlu dibina untuk mengurangi waktu mereka di jalan. Mereka juga membutuhkan keterampilan (life skill), untuk sekedar modal untuk mencri pekerjaan dalam kehidupannya, karena untuk kembali ke sekolah mereka sudah tidak mungkin bersama dengan teman sekolah yang di bawah usianya. Mereka membutuhkan keterampilan untuk dapat membantu hidup mereka selain mengamen di jalanan. Pendidikan dan Keterampilan yang memadai bagi mereka dapat dijadikan alat untuk berusaha atau membuka usaha sesuai kemampuan yang dimilikinya.

Pendidikan anak sangat dibutuhkan, karena anak merupakan generasi penerus bangsa. Selain itu, pembentukan karakter anak yang lebih baik bisa menciptakan generasi yang berkualitas. Salah satu komunitas anak jalan di kota Kendari yang mendukung Kendari sebagai Kota Layak Anak 
(KLA) adalah Komunitas Anak Jalanan Kota Kendari (Kojak). Kegiatan pembinaan anak jalan oleh Kojak di Kendari dilaksnakan setiap hari minggu. Pengurus Kojak menggelar berbagaia kegiatan, mulai dari belajar hingga bermain sebagai salah satu dukungan pemenuhan hak anak menuju Kendari kota layak anak. Dari sekitar 65 anak jalanan yang mereka data, hanya sekitar 50 anak yang aktif mengikuti kegiatan Kojak setiap minggunya. Dalam melakukan aktivitas itu, kerap kali para pengurus Kojak memberikan pemahaman pada para anak jalanan tentang hak dan tanggung jawab mereka sebagai anak, bukan sebagai tulang punggung keluarga untuk mencari uang. ${ }^{27}$ Dari pendekatan yang mereka lakukan, baik melalui anak dan orang tua, jumlah anak jalanan yang mangkal di persimpangan jalan lampu merah perlahan mulai berkurang. Selama ini yang mereka lakukan adalah mengajak mereka belajar sekali dalam seminggu. Hal ini dilakukan untuk mengajar mereka mengurangi waktu mereka berada di jalanan untuk meminta-minta.

Diharapkan kebijkan-kebijan pemerintah kota Kendari dalam rangka menuju kota layak anak (KLA) memperhatikan kehadiran anak jalanan, dapat melindungi, memajukan agar anak menggunakan waktunya tidak sepenuhnya dijalan. Demikian pula pemerintah memperhatikan peningkatan kesejahteraan keluarga tidak mampu agar anak mereka tidak dijadikan pekerja untuk memenuhi kebutuhan ekinomi keluarga. Pemerintah kota Kendari juga dapat memberikan beasiswa dan batuan kebutuhan sekolah bagi anak jalan agar mereka kembali ke sekolah. Bagi anak jalan yang bukan dari warga kota Kendari hendaknya dikoordinasikan dengan pemerentiah daerah asal mereka untuk program pembinaannya, agar tetap terbina dengan baik. Untuk memudahkan agar mereka dapat dipantau, maka pemerintah kota Kendari dapat menyediakan tempat atau asrama bagi yang tidak memiliki tempat tinggal untuk pembinaan pendidikan.

Suasana lingkungan sekolah ramah anak di Kota kendari dapat menjadi tempat bagi anak untuk belajar tentang kehidupan. Apalagi sekolah dengan program full day. Suasana aktivitas anak yang ada di masyarakat juga diprogramkan di sekolah sehingga anak tetap mendapatkan pengalaman-pengalaman yang seharusnya ia dapatkan di masyarakat. Bagi anak, lingkungan dan suasana yang memungkinkan untuk bermain sangatlah penting karena bermain bagi anak merupakan bagian dari hidupnya. Menurut UNESCO sekolah sebaiknya menjadi "Right to play" (hak bermain). Pada dasarnya, bermain dapat dikatakan sebagai bentuk miniatur dari masyarakat. Artinya, nilai-nilai yang ada di masyarakat juga ada di dalam permainan atau aktivitas bermain. Lingkungan sekolah kondusif

\footnotetext{
${ }^{27}$ Observasi dan wawancara kegiatan Kojak kota Kendari.
} 
untuk menumbuh-kembangkan potensi anak karena anak dapat mengekspresikan dirinya secara leluasa sesuai dengan dunianya.

\section{PENUTUP}

Anak jalanan di kota Kendari cenderung mengalami peningkatan dari tahun ke tahun, mereka bahkan datang dari luar kota Kendari seperti Sulawesi Selatan dan Sulawesi Barat. sebagian dari mereka bersekolah pada sekolah formal dan sebagian lainnya belajar melalui lembaga komunitas anak jalanan kota Kendari (Kojak), dan yang lainnya putus sekolah dengan alasan tidak mampu secara ekonomi. Mereka bekerja sebagai pengamen dan pengasong untuk memenuhi kebutuhan ekonomi keluarga. Sejauh ini belum tersedia model pendidikan khusus bagi anak jalanan di Kota Kendari yang difasilitasi oleh pemerintah. Dalam kerangka Kota Layak Anak (KLA) anak jalan perlu mendapatkan akses pendidikan, agar mereka mendapatkan hak belajar demi masa depan mereka.

\section{DAFTAR PUSTAKA}

Bartlett, Sheridan. "Urban Children and the Physical Environment". Amman, Jordan: International Conference on Childern and The City, 2002.

Bridgman, R. "Criteria for Best Practices in Building Child-Friendly Cities: Involving Young People in Urban Planning and Design". Canadian Journal of Urban Research. Vol. 13, No. 2, (2004): 337- 346.

Bagong, Suyanto dan Hariadi, Sri Sanituti. Krisis dan Child Abuse, Kajian Sosiologis tentang kasus Pelanggaran Hak Anak dan Anak-Anak yang membutuhkan Perlindungan Khusus (Child in Need of Special Protection). Surabaya: Airlangga University Press, 2002.

Erickson, F. "Qualitative Method in Reseach on Teaching". In M. C. Wittrock (Ed.) Handbook of Reseach on Teaching ( $3^{\text {rd }}$ ed.). New York. Macmillan, 1986.

Fauzi, Ahmad. "Usaha Transformasi Anak Jalanan Keluar Dari Posisi Anak Jalanan (Studi Perilau Sosial Anak Jalanan Di Provinsi Banten". Jurnal Eksistensi Pendidikan Luar Sekolah (E-Plus). Vol.1. No.1, (2016): 29-49.

Karsten, L\&Van Vliet, W. "Children in the City: Reclaiming the Street". International Journal of Youth and Environments. Vol. 16, No. 1, (2006): 151-167.

Milles, Matthew B. Huberman, Michael A. Qualitative Data Anlysis; A Sourchbook of New Methods. London: Sage Publication, Baverly Hills, 1984. 
Nasution, S. Metode Penelitian Naturalistik Kualitatif. Bandung. Tarsito, 1996.

Patilima, Hamid. Persepsi Anak Mengenai Lingkungan Kota- Studi Kasus Di Kelurahan Kwitang, Jakarta Pusat. Tesis. Jakarta: Kajian Pengembangan Perkotaan, Pascasarjana Universitas Indonesia, 2004.

Riggio, E. "Child Friendly Cities: Good Governance in the Best Interest of the Child". International Journal of Environment and Urbanization. Vol. 14, No. 2, (2002): 45-58.

Saldana, Johny. The Coding Manual fo Qualitative Resesarch. London: Sage Publication, 2009.

Schutz's, A. "Phenomenology, Ethnomethodology and Interpretative Practice. In N. K. Denzin \& Yvonna S. Lincoln, Hand Book of Cualitative Research. London: Sage Publication Inc, 1970.

Strauss, A. \& Corbin, J. Basics of Qualitatif Resesrach; Grounded Theory Procedures and Techniqus. Newbury Park. CA: Sage Publication. Inc, 1990.

Suyanto, Bagong, \& Hariadi, Sri Sanituti. Krisis dan Child Abuse, Kajian Sosiologis tentang Kasus Pelanggaran Hak Anak dan Anak-Anak yang Membutuhkan Perlindungan Khusus (Child in Need of Special Protection). Surabaya: Airlangga University Press, 2002.

\section{Perundang-Undangan:}

Peraturan Menteri Negara Pemberdayaan Perempuan Nomor 2 Tahun 2009 mengenai aturan Kebijakan/Kota Layak Anak

Peraturan Menteri Pemberdayaan Perempuan dan Perlindungan Anak No 12 Tahun 2011 mengenai Indikator Kabupaten dan Kota Layak Anak.

\section{Website:}

Child Friendly Cities. 2011. What is a Child Friendly City? http:// www.childfriendlycities.org /en/overview/ what-is-a-child-friendlycity. diakses tanggal 08 Mei 2016.

http://megapolitan. kompas.com/. diakses, 14 November 2016 